Document downloaded from:

http://hdl.handle.net/10251/47642

This paper must be cited as:

Andrade Morelli, S.; Ruiz Sanchez, E.; Granell Romero, E.; Lloret, J. (2013). Energy Consumption of Wireless Network Access Points. Lecture Notes of the Institute for Computer Sciences, Social-Informatics and Telecommunications Engineering, LNICST. 113:81-91. doi:10.1007/978-3-642-37977-2_8.

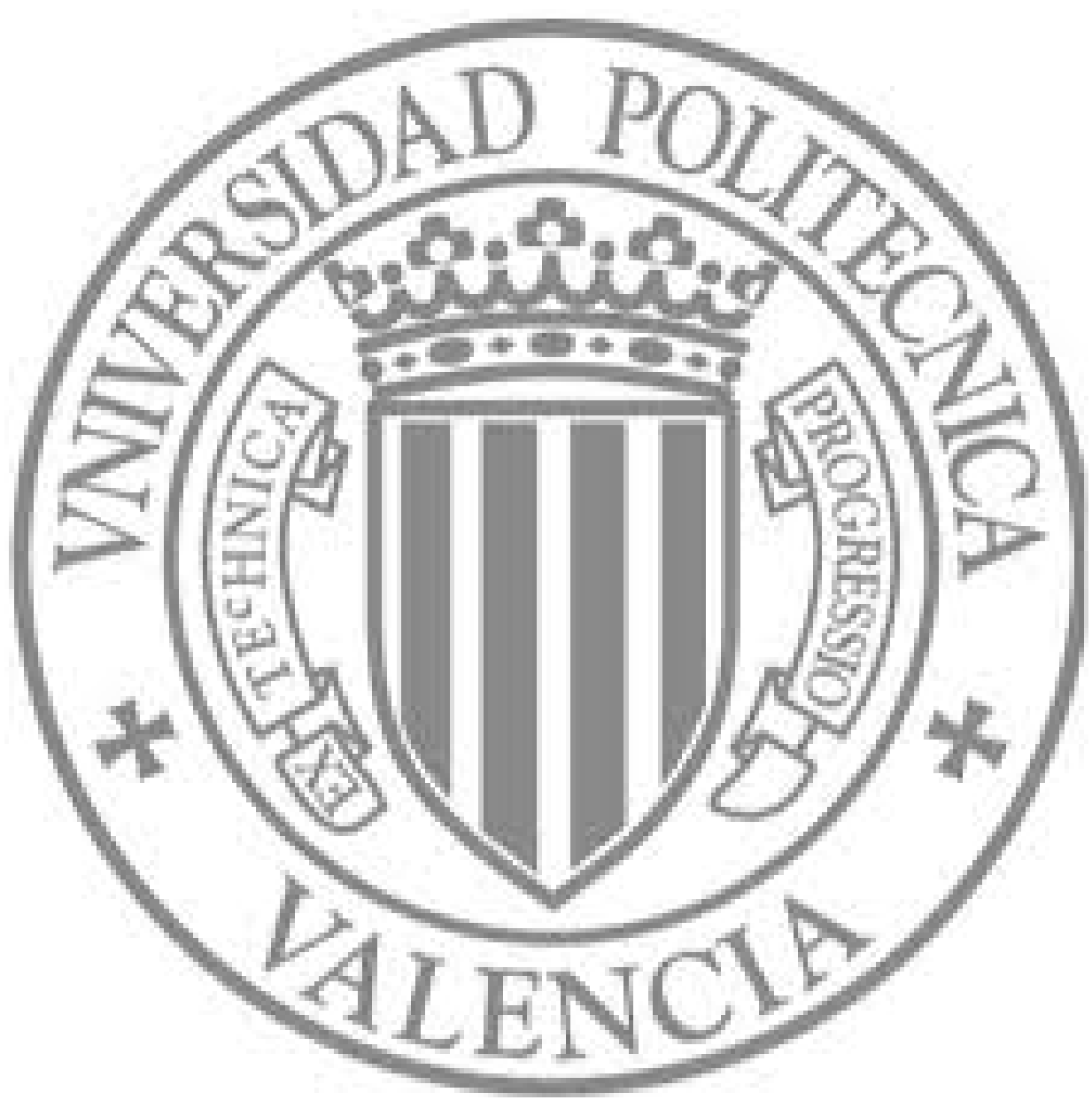

The final publication is available at

http://dx.doi.org/10.1007/978-3-642-37977-2_8

Copyright Springer Verlag 


\title{
Energy Consumption of Wireless Network Access Points
}

\author{
Sebastián Andrade-Morelli, Eduardo Ruiz-Sánchez, Emilio Granell, Jaime Lloret \\ Universidad Politécnica de Valencia, \\ Camino Vera s/n, 46022, Valencia, Spain \\ seanmodepsg.upv.es, edruisandepsg.upv.es, \\ emgraro@posgrado.upv.es, jlloret@dcom.upv.es
}

\begin{abstract}
The development of low cost technology based on IEEE 802.11 standard permits to build telecommunication networks at low cost, allowing providing Internet access in rural areas in developing countries. The lack of access to the electrical grid is a problem when the network is being developed in rural areas, so that wireless access points should operate using solar panels and batteries. Many cases can be found where the energy consumption becomes a key point in wireless network design. In this paper we present a comparative study of the energy consumption of several wireless network access points. We will compare the energy consumption of different brands and models, for several operation scenarios and operating modes. Obtained results allow us to achieve the objective of this article, that is, promote the development of wireless communication networks energetically efficient.
\end{abstract}

Keywords: Energy consumption, Power Consumption, Access Points, Green Networks, Smart Grid.

\section{Introduction}

In recent years, the network devices have evolved to improve network performance [1]. These improvements are also happening in wireless network devices reducing its economical cost. The development of low cost technology based on IEEE 802.11 [2] has facilitated the development of applications for monitoring natural areas through wireless sensor networks (WSN) [3] and the development of data networks for Internet access for end users.

The popularization of mobile devices allowing wireless access to networks is motivating the municipalities to provide an independent community network to provide different services to citizens [4].

Furthermore, this type of community networks can offer all kinds of applications for-profit and not-for-profit [5]. The municipalities can use these networks to promote its economical development, offering applications for business and tourism to citizens. At the same time, these networks can be used for remote monitoring of parking meters and street lights even the automation of other services [6]. Nowadays, wireless access devices can just change the data link layer, acting as a wireless access 
point, or even route between networks, where several common routing protocols can be configured [7].

Wireless networks offer the possibility to build telecommunications networks at low cost, allowing providing Internet access in rural areas in developing countries [8]. The lack of access to the electrical grid is a problem when the network is being developing in rural areas. One possible solution to this problem is to power network access points using solar panels and batteries, so its power consumption becomes a key issue to ensure its operation [9]. Moreover, some researchers are proposing new intelligent algorithms for the MAC layer that improve the performance of the network [10] and, thus, reduce the energy consumption of the wireless devices [11].

In this paper, we present a study of the energy consumption in wireless access points, depending on the brand, model and its configuration. With this study we also sought to determine if the wireless technology and frequency band used affect energy usage in the access point. These measures will serve as a tool for designing energy efficient wireless networks.

The rest of the paper is structured as follows, Section 2 shows several previous works and researches regarding to consumption and saving energy in wireless access points. In Section 3 are shown the topologies and the description of the characteristics of the access points used to perform these tests. The obtained measurement results and the discussion are shown in Section 4. Finally, the conclusions and future works are shown in Section 5.

\section{Related Work}

Currently, there is a great interest in the analysis of the power consumption of network devices because ecological and economical reasons. L.M. Feeney et al. in [12] present a study about the energy consumption of wireless networks interfaces in ad-hoc networks. Several authors have focused their analysis on energy consumption from the point of view of the development of software tools. In [13] the authors present intelligent equipment allowing the energy saving, using smart routing. These tools intend to control the consumption of wireless networks. Another example is the work presented in [14], where T. Chen et al. proposed a series of strategies for achieving or at least approaching the goals of establishing a "green network", these solutions are based on the correct choice of the IEEE 802.11 standard, as well as the different devices to form Wireless Networks.

S. Sendra et al. present in [15] different techniques for saving energy in wireless sensor networks. The paper shows how a sensor node must be and the relationship between the quantity of information transmitted and the power consumption by the hardware used. Authors have also compared several MAC and routing protocols that have been designed to optimize the power consumption without compromising the data delivery in wireless sensor and ah-hoc networks.

But as far as we know there is no study focused on the energy consumption of wireless access points from the point of view of their model and their configuration. With our work we want to offer a tool for developing and maintaining wireless telecommunications networks energetically efficient. So the study presented in this 
paper serves as a reference both to the development of wireless networks in rural areas of developing countries and to reduce consumption in wireless networks in general.

\section{Scenarios and Hardware Description}

In order to carry out our measurements, we need to test the performance of multiple access points of different brands and models. In this section we will see the technical characteristics of the selected devices for our study and describe the topologies used to fulfil our measurements. To measure the energy consumption, we used an electronic device called "Kill a Watt". This device is able to measure the electrical voltage, current and power parameters with $1 \%$ of measurement error.

We need different network topologies to compare how affect to wireless access points energy consumption all its configurable parameters, especially, when we compare energy consumption between a completely wireless network and a halfwired network. Figure 1 shows the two topologies used to carry out our study. On one hand in the Topology 1, the access point is used to connect two endpoints, the first one with a wireless connection and the second one with a wired connection, in the other hand in Topology 2, the access point is used to connect two endpoints with wireless connections.

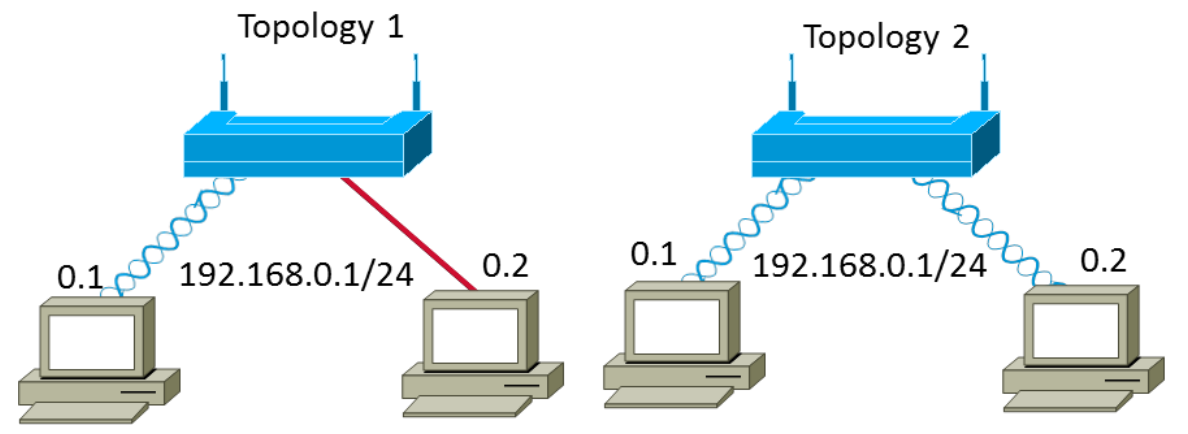

Fig. 1. Network topologies.

Table 1 shows wireless network access points used in our study and their relevant characteristics.

Table 1 Wireless network access points and its relevant characteristics.

\begin{tabular}{lccccccc}
\hline & $\begin{array}{c}\text { Frequency } \\
\text { band (Ghz) }\end{array}$ & $\begin{array}{c}\text { Operating } \\
\text { temperature } \\
\left({ }^{\circ} \mathrm{C}\right)\end{array}$ & $\begin{array}{c}\text { Internal } \\
\text { memory } \\
(\mathrm{MB})\end{array}$ & $\begin{array}{c}\text { Flash } \\
\text { memory } \\
(\mathrm{MB})\end{array}$ & $\begin{array}{c}\text { Max data } \\
\text { transfer rate } \\
(\mathrm{Mbps})\end{array}$ & $\begin{array}{c}\text { Wireless } \\
\text { protocol }\end{array}$ & $\begin{array}{c}\text { Data } \\
\text { transmission } \\
\text { protocol }\end{array}$ \\
\hline $\begin{array}{l}\text { Cisco Systems AIR- } \\
\text { AP1131AG-E-K9 }\end{array}$ & 2.4 & $0-40$ & 32 & 16 & 108 & $\begin{array}{c}\text { IEEE } \\
802.11 \mathrm{a} / \mathrm{b} / \mathrm{g}\end{array}$ & Fast Ethernet \\
$\begin{array}{l}\text { Cisco Linksys } \\
\text { WRT54GL }\end{array}$ & 2.4 & $0-40$ & 16 & 4 & 54 & $\begin{array}{c}\text { IEEE } \\
802.11 \mathrm{~b} / \mathrm{g} \\
\text { IEEE }\end{array}$ & $\begin{array}{c}\text { Ethernet, Fast } \\
\text { Ethernet }\end{array}$ \\
$\begin{array}{l}\text { Cisco Linksys } \\
\text { WRT320N-EZ }\end{array}$ & $2.4 / 5.0$ & $0-40$ & 32 & 8 & 300 & $802.11 \mathrm{~b} / \mathrm{g} / \mathrm{a} /$ & $\begin{array}{c}\text { Ethernet, Fast } \\
\text { Ethernet }\end{array}$
\end{tabular}




\begin{tabular}{|c|c|c|c|c|c|c|c|}
\hline $\begin{array}{l}\text { D-link DWL- } \\
2000 \mathrm{Ap}+\end{array}$ & 2.4 & $0-55$ & 16 & 4 & 54 & $\begin{array}{c}\mathrm{n} \\
\text { IEEE } \\
802.11 \mathrm{~b} / \mathrm{g}\end{array}$ & $\begin{array}{c}\text { Ethernet, Fast } \\
\text { Ethernet }\end{array}$ \\
\hline Avaya AP-I & 2.4 & $0-40$ & 16 & 4 & 11 & $\begin{array}{l}\text { IEEE } \\
802.11 \mathrm{~b}\end{array}$ & Ethernet \\
\hline Ovislink WX-1590 & 2.4 & $0-55$ & 16 & 4 & 11 & $\begin{array}{c}\text { IEEE } \\
802.11 \mathrm{~b}\end{array}$ & Ethernet \\
\hline
\end{tabular}

For each wireless access point we define two different measurement cases:

- First case: the measure of energy consumed at starting state and at steady state.

- Second case: the measure of energy consumed for both topologies, for each wireless protocol and frequency band permitted by the access point:

- For sending an echo from PC 1 to PC 2.

$\circ$ For sending a file of 2.45 GB from PC 1 to PC 2 .

\section{Result of measurements}

After configuring the different wireless access points we have tested it using both topologies. The energy measurements obtained from the tests are shown in several tables and graphs with the goal of compare their values. With these comparatives we will determine which access point consumes less energy, and how affect the different parameters to energy consumption.

\subsection{Measurements for Cisco Systems AIR-AP1131AG-E-K9.}

The first access point under study is a Cisco Systems AIR-AP1131AG-E-K9. This access point can be configured only using protocols IEEE $802.11 \mathrm{a}$, IEEE $802.11 \mathrm{~b}$ and IEEE $802.11 \mathrm{~g}$ and its power consumption at starting state is $5.1 \mathrm{~W} \cdot \mathrm{h}$ and at steady state is $5.4 \mathrm{~W} \cdot \mathrm{h}$. In Table 2 we present the values of power consumption in case 2 and in Figure 2 we represent these values. As we can see in Figure 2 the power consumed by this device during transmission is always between $10 \mathrm{~W} \cdot \mathrm{h}$ and $11 \mathrm{~W} \cdot \mathrm{h}$. We observe an increase of $2 \%$ in power consumption in air-air communication compared with air-cable communication. We can also see how the protocol IEEE $802.11 \mathrm{~b}$ usually consumes less energy except in the case of sending a file in the topology 1. Finally, the increase of power consumption for activation of the MAC filter is confirmed as expected, in this case becomes $2 \%$.

Table 2. Measurements for the second case.

\begin{tabular}{|c|c|c|c|c|c|c|}
\hline \multicolumn{7}{|c|}{ Power consumption (W.h) } \\
\hline & $\begin{array}{c}\text { IEEE } \\
802.11 \mathrm{a}\end{array}$ & $\begin{array}{c}\text { IEEE } \\
802.11 b\end{array}$ & $\begin{array}{c}\text { IEEE } \\
802.11 \mathrm{~g}\end{array}$ & $\begin{array}{c}\text { IEEE } \\
\text { 802.11a with } \\
\text { MAC filter }\end{array}$ & $\begin{array}{c}\text { IEEE } \\
802.11 \mathrm{~b} \text { with } \\
\text { MAC filter }\end{array}$ & $\begin{array}{c}\text { IEEE } \\
\text { 802.11g with } \\
\text { MAC filter }\end{array}$ \\
\hline \multicolumn{7}{|l|}{ Topology 1} \\
\hline Sending echo & 10.3 & 10.2 & 10.2 & 10.4 & 10.2 & 10.3 \\
\hline Sending file & 10.5 & 10.5 & 10.4 & 10.7 & 10.6 & 10.4 \\
\hline
\end{tabular}




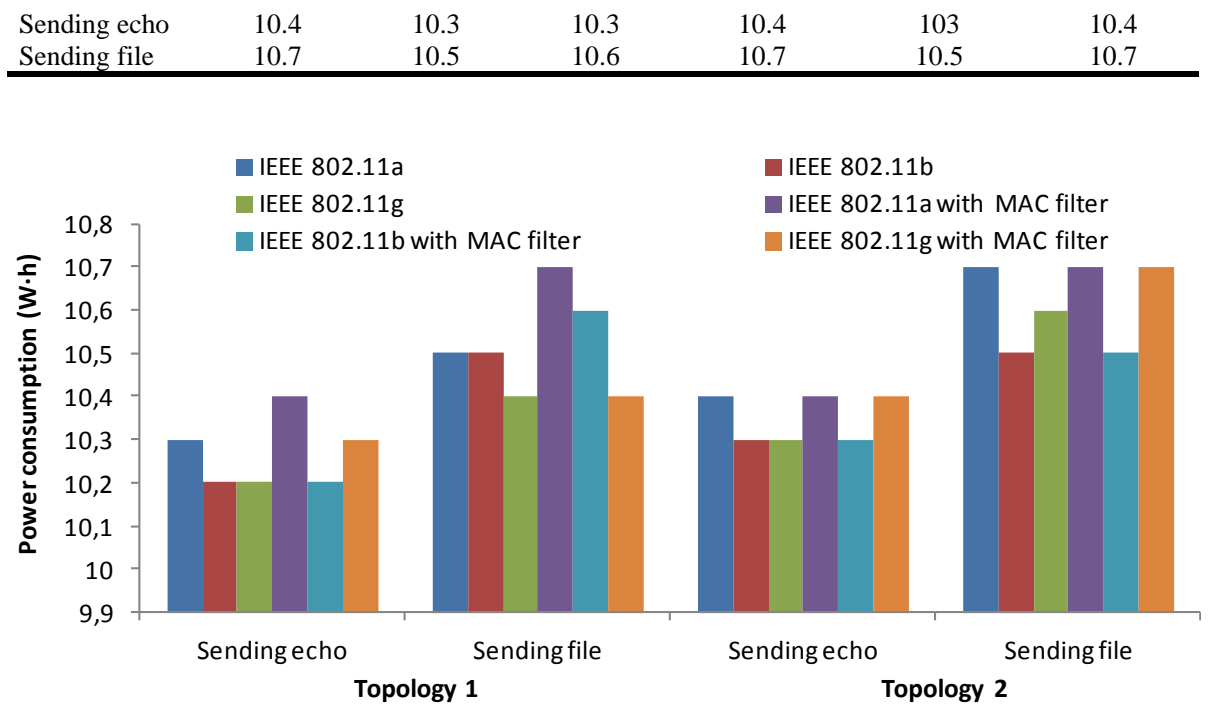

Fig. 2. Power consumption for second case for Cisco Systems AIR-AP1131AG-E-K9.

\subsection{Measurements for Cisco Linksys WRT54GL}

The second access point that we will discuss is a Cisco Linksys WRT54GL. This access point allows only protocols IEEE $802.11 \mathrm{~b}$ and IEEE $802.11 \mathrm{~g}$ and its power consumption is $5.2 \mathrm{~W} \cdot \mathrm{h}$ at starting state and $5.7 \mathrm{~W} \cdot \mathrm{h}$ at steady state. In Table 3 are shown the values of power consumption obtained for the second case of measurements and in Figure 3 its representation. As we can observe in Figure 3, the energy consumed by this access point is considerably less than the consumed by the previous model. This model consumes around 40\% less energy. From the obtained values, is observed for this device that IEEE $802.11 \mathrm{~g}$ protocol consumes less energy than IEEE $802.11 \mathrm{~b}$ protocol, and as in the previous model, the activation of the MAC filter increase the energy consumption, the air-air transmission consume more energy that the air-cable transmission and sending a file also consume more than sending an echo.

Table 3. Measurements for the second case.

\begin{tabular}{|c|c|c|c|c|}
\hline \multicolumn{5}{|c|}{ Power consumption $(\mathrm{W} \cdot \mathrm{h})$} \\
\hline & IEEE & IEEE & IEEE $802.11 \mathrm{~b}$ & IEEE $802.11 \mathrm{~g}$ with \\
\hline & $802.11 \mathrm{~b}$ & $802.11 \mathrm{~g}$ & with MAC filter & MAC filter \\
\hline \multicolumn{5}{|l|}{ Topology 1} \\
\hline Sending echo & 6 & 6 & 6.1 & 6.2 \\
\hline Sending file & 6.2 & 6.1 & 6.2 & 6.2 \\
\hline \multicolumn{5}{|l|}{ Topology 2} \\
\hline Sending echo & 6 & 6.1 & 6.1 & 6.1 \\
\hline Sending file & 6.4 & 6.3 & 6.5 & 6.3 \\
\hline
\end{tabular}




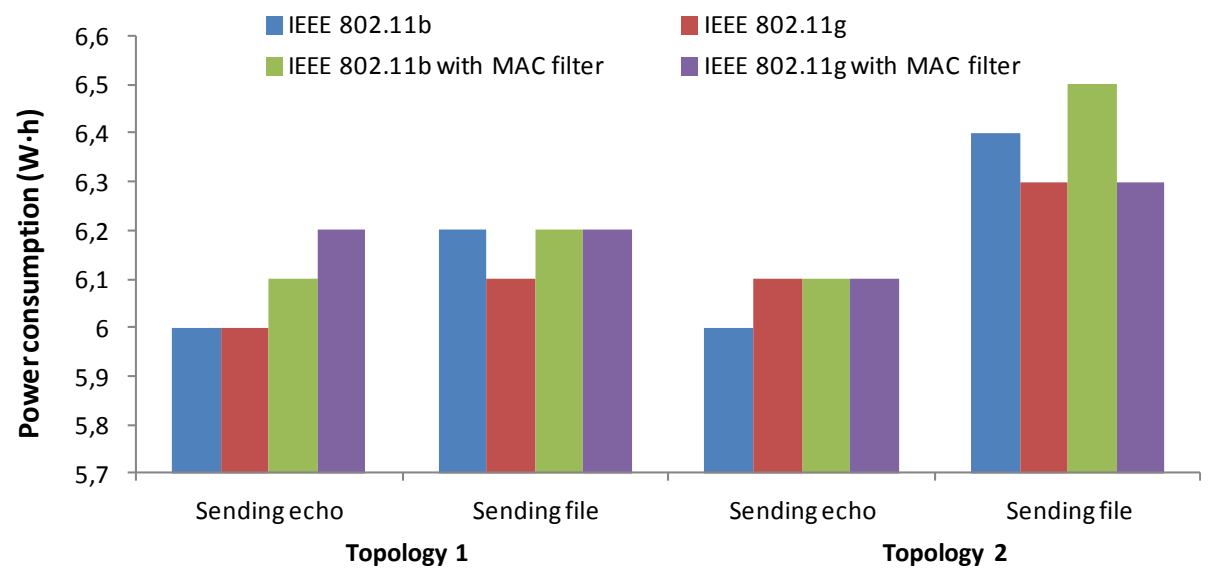

Fig. 3. Power consumption for second case for Cisco Linksys WRT54GL.

\subsection{Measurements for Cisco Linksys WRT320N-EZ}

In this case we will analyse the energy consumption of the access point Cisco Linksys WRT320N-EZ. This device consumes $4.5 \mathrm{~W} \cdot \mathrm{h}$ at starting state and $4.8 \mathrm{~W} \cdot \mathrm{h}$ at steady state. The values of the energy consumed for the second case of measurements is shown in Table 4 and in Figure 4 are represented this values. This access point allows the protocols IEEE 802.11a, IEEE 802.11b, IEEE 802.11g and IEEE $802.11 \mathrm{n}$. As we can see, this device consumes less energy than the previously studied. We note that the IEEE $802.11 \mathrm{n}$ protocol is the one that consumes less energy but there is two cases in which consumes 1\% more energy than IEEE 802.11g. We observed the same effect previously regarding the activation of the MAC filter comparing topologies and type of communication.

Table 4. Measurements for the second case.

\begin{tabular}{|c|c|c|c|c|c|c|c|c|}
\hline & \multicolumn{8}{|c|}{ Power consumption $(\mathrm{W} \cdot \mathrm{h})$} \\
\hline & $\begin{array}{c}\text { IEEE } \\
802.11 \mathrm{a}\end{array}$ & $\begin{array}{l}\text { IEEE } \\
802.11 \mathrm{~b}\end{array}$ & $\begin{array}{c}\text { IEEE } \\
802.11 \mathrm{~g}\end{array}$ & $\begin{array}{l}\text { IEEE } \\
802.11 \mathrm{n}\end{array}$ & $\begin{array}{c}\text { IEEE } \\
802.11 \mathrm{a} \\
\text { with MAC } \\
\text { filter }\end{array}$ & $\begin{array}{c}\text { IEEE } \\
802.11 \mathrm{~b} \\
\text { with MAC } \\
\text { filter }\end{array}$ & $\begin{array}{c}\text { IEEE } \\
802.11 \mathrm{~g} \\
\text { with } \\
\text { MAC } \\
\text { filter }\end{array}$ & $\begin{array}{c}\text { IEEE } \\
802.11 \mathrm{n} \\
\text { with } \\
\text { MAC } \\
\text { filter }\end{array}$ \\
\hline \multicolumn{9}{|l|}{ Topology 1} \\
\hline Sending echo & 5.3 & 5.3 & 5.2 & 5.3 & 5.3 & 5.3 & 5.3 & 5.3 \\
\hline Sending file & 5.4 & 5.4 & 5.4 & 5.3 & 5.5 & 5.5 & 5.4 & 5.4 \\
\hline Topology 2 & & & & & & & & \\
\hline Sending echo & 5.3 & 5.3 & 5.3 & 5.3 & 5.4 & 5.3 & 5.3 & 5.4 \\
\hline Sending file & 5.5 & 5.6 & 5.5 & 5.4 & 5.5 & 5.7 & 5.6 & 5.5 \\
\hline
\end{tabular}




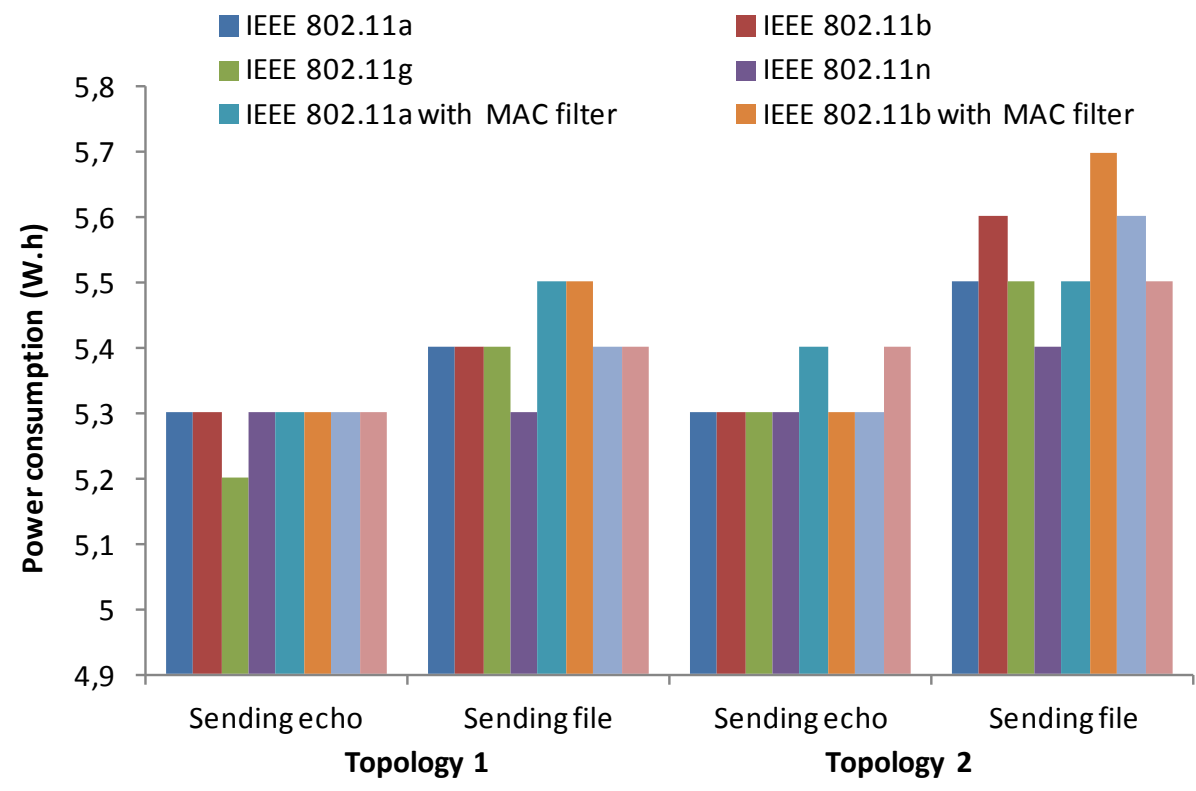

Fig. 4. Power consumption for second case for Cisco Linksys WRT320N-EZ.

\subsection{Measurements for D-link DWL-2000Ap+}

The fourth case analyses the consumption of the access point D-Link Access Point DWL 2000AP. The power consumption in the first case of measurement for this device is $3.4 \mathrm{~W} \cdot \mathrm{h}$ at starting state and $4.8 \mathrm{~W} \cdot \mathrm{h}$ at steady state. This access point allows only protocols IEEE $802.11 \mathrm{~b}$ and IEEE $802.11 \mathrm{~g}$. In Table 5 are shown the values of power consumption obtained for the second case of measurements and in Figure 5 its representation. As we can observe in Figure 5, the energy consumed by this access point is considerably less than the consumed by Cisco models. This device consumes approximately 16\% less energy than the model of Cisco (Cisco Linksys WRT54GL) offering the same services. In this device IEEE $802.11 \mathrm{~b}$ protocol consumes less energy than IEEE $802.11 \mathrm{~g}$ protocol, but respect to extra consumption generated by the MAC filter, by the second topology and the transmission of a file, the conclusions are the same as in the previous access points. 
Table 5. Measurements for the second case.

\begin{tabular}{lcccc}
\hline \multicolumn{5}{c}{ Power consumption $(\mathrm{W} \cdot \mathrm{h})$} \\
\hline & $\begin{array}{c}\text { IEEE } \\
802.11 \mathrm{~b}\end{array}$ & $\begin{array}{c}\text { IEEE } \\
802.11 \mathrm{~g}\end{array}$ & $\begin{array}{c}\text { IEEE 802.11b with } \\
\text { MAC filter }\end{array}$ & $\begin{array}{c}\text { IEEE 802.11g } \\
\text { with MAC filter }\end{array}$ \\
$\begin{array}{l}\text { Topology 1 } \\
\text { Sending echo }\end{array}$ & 5 & 5.1 & 5.1 & 5.2 \\
Sending file & 5.1 & 5.2 & 5.2 & 5.2 \\
Topology 2 & & & & 5.2 \\
Sending echo & 5.1 & 5.1 & 5.2 & 5.4 \\
Sending file & 5.3 & 5.3 & 5.4 & \\
\hline
\end{tabular}

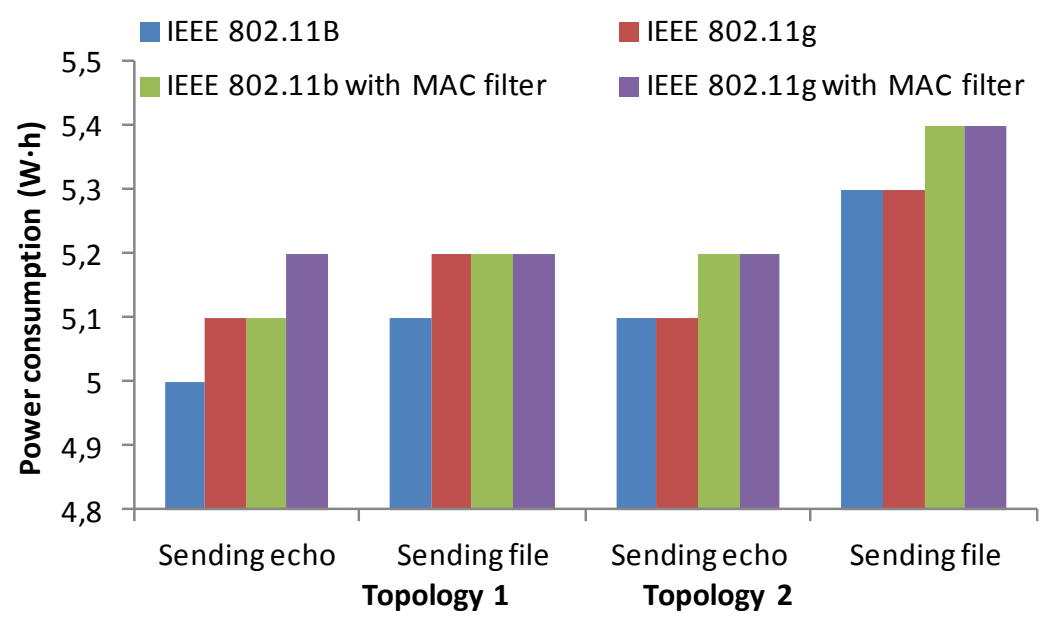

Fig. 5. Power consumption for second case for DWL-2000Ap+

\subsection{Measurements for Avaya AP-I}

The fifth case analyses the consumption of the access point Avaya Access Point I. The capabilities of this access point are more limited compared with the previous ones and its consumption is $2.8 \mathrm{~W} \cdot \mathrm{h}$ at starting state and $3.2 \mathrm{~W} \cdot \mathrm{h}$ at steady state. This device allows only protocol IEEE $802.11 \mathrm{~b}$. In Table 6 are shown the values of power consumption obtained for the second case of measurements and in Figure 6 its representation. As we can see in Figure 6 this device consumes less energy than the previous ones, an explanation for this fact is its limited hardware. In this device the increase in the energy consumed introduced by the use of the MAC filter is approximately $3 \%$. For the rest of parameters studied, we observe the same behaviour observed on the rest of access points. 
Table 6. Measurements for the second case.

\begin{tabular}{lcc}
\hline \multicolumn{3}{c}{ Power consumption $(\mathrm{W} \cdot \mathrm{h})$} \\
\hline & IEEE & $\begin{array}{c}\text { IEEE } 802.11 \mathrm{~b} \text { with } \\
\text { MAC filter }\end{array}$ \\
Topology 1 & $802.11 \mathrm{~b}$ & 3.3 \\
Sending echo & 3.2 & 3.5 \\
Sending file & 3.4 & \\
Topology 2 & & 3.4 \\
Sending echo & 3.3 & 3.5 \\
Sending file & 3.5 & \\
\hline
\end{tabular}

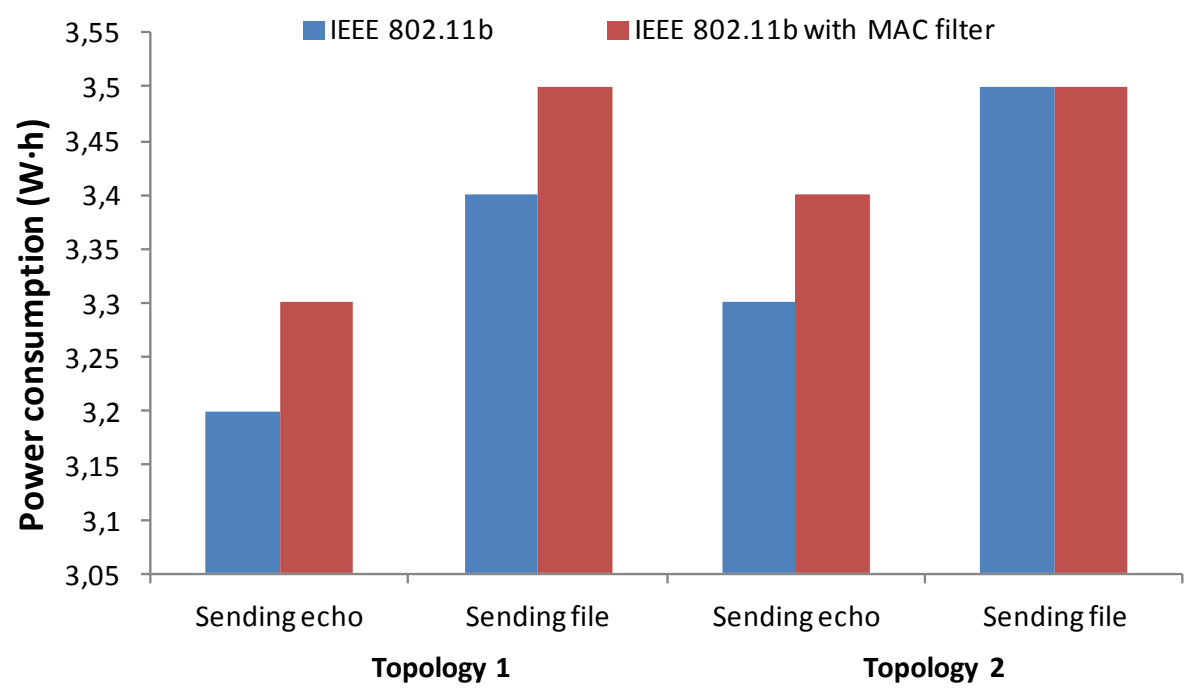

Fig. 6. Power consumption for second case for Avaya AP-I.

\subsection{Measurements for Ovislink WX-1590}

The sixth case analyses the consumption of the Ovislink Access point WX-1590. This access point has limited capabilities as the previous one, but this device consumes around $40 \%$ more energy. Its consumption is $4.8 \mathrm{~W} \cdot \mathrm{h}$ at starting state and $5.4 \mathrm{~W} \cdot \mathrm{h}$ at steady state. This device allows only protocol IEEE $802.11 \mathrm{~b}$.

Table 7 shows the values of power consumption obtained for the second case of measurements and Fig. 7 shows its representation. For the rest of studied parameters, we observe the same behaviour observed on the rest of access points. 
Table 7. Measurements for the second case.

\begin{tabular}{lcc}
\hline \multicolumn{3}{c}{ Power consumption $(\mathrm{W} \cdot \mathrm{h})$} \\
\hline & IEEE & $\begin{array}{c}\text { IEEE 802.11b } \\
\text { with MAC filter }\end{array}$ \\
Topology 1 & $802.11 \mathrm{~b}$ & 5.4 \\
Sending echo & 5.5 & 5.5 \\
Sending file & 5.5 & \\
Topology 2 & & 5.6 \\
Sending echo & 5.5 & 6.2 \\
Sending file & 6 & \\
\hline
\end{tabular}

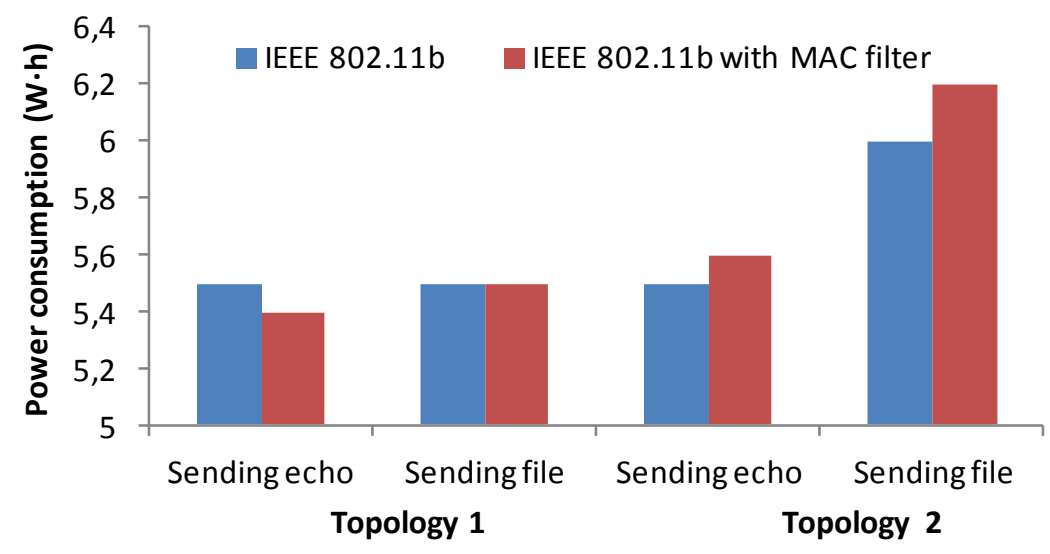

Fig. 7. Power consumption for second case for Ovislink WX-1590.

\section{Conclusions}

In this paper we present a study on energy consumption in wireless access points. We have measured the energy consumption at the starting and steady states. We also measured the energy when there are devices sending echoes and files between them through the access point and with the MAC filter is active and disabled in two different network topologies. In our study we have shown that energy consumption increases in all studied models when MAC filter is enabled, sending a file and when the communication between computers is air to air. We have also seen that models with higher capabilities consume more energy than models with reduced capabilities. The results of this study demonstrate that it is possible to optimize the energy efficiency of the network using the access point models and parameters suitable to the requirements of the network. These factors are very important in places where power consumption is critical.

In future work, we will extend our study to other telecommunication network devices such as routers and switches. The choice of network devices is a key issue in energy savings in telecommunication networks, so with these studies we sought to 
determine which devices and their configuration are more suitable for the development of green communications networks.

\section{References}

[1] K. Khoa Nguyen, B. Jaumard, "Routing Engine Architecture for Next Generation Routers: Evolutional Trends", Network Protocols and Algorithms, vol. 1, no. 1, pp. 62-85, September 2009.

[2] IEEE Std 802.11 (2007) "IEEE Standard for Information technology -

Telecommunications and information exchange between systems -Local and metropolitan area networks - Specific requirements - Part 11: Wireless LAN Medium Access Control (MAC) and Physical Layer (PHY) Specifications", Institute of Electrical and Electronics Engineers, pp.1-1184, New York, USA.

[3] J. Lloret, M. Garcia, D. Bri and S. Sendra, "A Wireless Sensor Network Deployment for Rural and Forest Fire Detection and Verification”, Sensors, vol. 9, no. 11, pp. 8722-8747. October 2009.

[4] A. Tapia, C. Maitland and M. Stone, "Making IT work for Municipalities: Building municipal wireless networks", Government Information Quarterly, vol. 23, no. 3, pp. 359$380,2006$.

[5] R. van Drunen, J. Koolhaas, H. Schuurmans and M. Vijn, "Building a Wireless Community Network in the Netherland", USENIX '03 / Freenix Annual Technical Conference Proceedings, pp. 219-230, San Antonio, Texas, USA, June 9-14, 2003.

[6] A. Powelland L.R. Shade, "Going Wi-Fi in Canada: Municipal and Community Initiatives", Canadian Research Alliance for Community Innovation and Networking, 2005.

[7] Sendra, S., Fernández, P. A., Quilez, M. A., Lloret, J.: Study and Performance of Interior Gateway IP routing Protocols. Network Protocols and Algorithms. Vol. 2, Issue 4, pp. 88117. December 2010.

[8] H. Galperin, "Wireless Networks and Rural Development: Opportunities for Latin America", Information Technologies and International Development, vol. 2, no. 3, pp. 47$56,2005$.

[9] Michael Segal, "Improving lifetime of wireless sensor networks", Network Protocols and Algorithms, Vol 1, No 2, pp. 48-60, December 2009.

[10] Ahmad Abed Elellah Momani, Muneer Bani Yassein, Omar Darwish, Saher Manaseer, Wail Mardini, Intelligent Paging Backoff Algorithm for IEEE 802.11 MAC Protocol, Network Protocols and Algorithms, Vol 4, No 2. Pp. 108-123. June 2012.

[11] Ahlam Hashim Mohsin, Kamalrulnizam Abu Bakar, Adebanjo Adekiigbe, kayhan zrar ghafoor, A Survey of Energy-aware Routing protocols in Mobile Ad-hoc Networks: Trends and Challenges, Network Protocols and Algorithms, Vol 4, No 2. Pp. 82-107. June 2012.

[12] L.M. Feeneyand M. Nilsson, "Investigating the Energy Consumption of a Wireless Network Interface in an Ad Hoc Networking Environment", INFOCOM 2001. Twentieth Annual Joint Conference of the IEEE Computer and Communications Societies. Proceedings. IEEE, vol. 3, pp. 1548-1557, Anchorage, Alaska, April 22-26, 2001.

[13] J. Barbancho, C. León, F.J. Molina and A. Barbancho, "Using artificial intelligence in routing schemes for wireless networks", Computer Communications, vol. 30, no. 14-15, pp. 2802-2811, October 2007.

[14] C. Tao, Y. Yang, Z. Honggang, K. Haesik and K. Horneman, "Network energy saving technologies for green wireless access networks", IEEE Wireless Communications, vol. 18 , no. 5 , pp. $30-38,2011$. 
[15] S. Sendra, J. Lloret, M. Garcia and J.F. Toledo, "Power saving and energy optimization techniques for Wireless Sensor Networks", Journal of Communications, vol. 6, no 6, pp. 439-459, 2011. 